substance, are left at liberty to consolidate firmly near an unoffending though foreign body.

It would carry me far beyond the limited time which, by the rules of the Association, is slone at my disposal, were I to enter into the various applications of the antiseptic principle in the several special departments of surgery.

There is, however, one point more that $I$ cannot but advert to-namely, the influence of this mode of treatment upon the general healthiness of an hospital. Previously to its introduction, the two large wards in which most of my cases of accident and of operation are treated were amongst the unhealthiest in the whole surgical division of the Glasgow Royal Infirmary, in consequence, apparently, of those wards being unfavourably placed with reference to the supply of fresh air; and I have felt ashamed, when recording the results of my practice, to have so often to allude to hospital gangrene or pyrmia. It was interesting, though melancholy, to observe that, whenever all, or nearly all, the beds contained cases with open sores, these grievous complications were pretty sure to show themselves; so that I came to welcome simple fractures, though in themselves of little interest either for myself or the students, because their presence diminished the proportion of open sores among the patients. But since the antiseptic treatment has been brought into full operation, and wounds and abscesses no longer poison the atmosphere with putrid exhalations, my wards, though in other respects under precisely the same circumstances as before, have completely changed their character; so that during the last nine montius not a single instance of pyæmia, hospital gangrene, or erysipelas has occurred in them. As there appears to be no doubt regarding the cause of this change, the importance of the fact can hardly be exaggerated.

\section{ON IDIOCY AND ITS RELATION TO TUBERCULOSIS.}

\section{BI J. LANGDON H. DOWN, M.D. LoND.;} PHYSICIAN TO THE TARLSWOOD ASTLUAT;

ASSISTANT-PHYSICLAN TO, AND TRCTURRR ON MATERIA MIEDICA AT, THE LONDON HOSPITAL,

The causes which have been assigned as productive of idiocy are numerous, and some have received special advocacy. Thus we are asked to belicve that one of the most profound misfortunes which afflicts our race-which to a great extent blots ont the characteristics of man, and approximates him to the lower animals-arises from sucking the thumb; and that if we could prevent a "fruitless sucking" idiocy would be immensely diminished, even if it did not cease to exist. Others, with wore show of reason, urge the intermarriage of blood relations as the prevailing cause; and so far does a belief in the potency of this latter element permeate society that I have been often gravely asked whether intermarriage of relations is not the cause of the idiocy of three-fourths of the cases which come under my observation. No one who has had an opportunity of investigating the influences which are at work in the production of congenital mental diseases can fail to be struck with the fact that they are, for the most part, to be traced to some inberent vice of constitution in the progenitors. He will discover in the parents elements of degeneracy which must have bad their share in producing the catastrophe. He will notice how by degrees the stock has deteriorated. He will be able to estimate how intemperance or sensuality leads slowly but surely to idiocy-how physical weakness of the parents culminates in the mental blight of the child.

Amongst the influences which have been regarded as connected with idiocy, very little attention has been given to that of tuberculosis, and $I$ ain not aware that any observations have been made with reference to the connexion of these two maladies.

Several writers have discussed the relations between insanity and tuberculosis, and have, I think, made it tolerably evident that there is more than an accidental connexion between them.

At the Earlswood Asylum, where the following observations have been made, the subjects of the inquiry are not likely to present an unfair proportion of tubercular idiots. Rather would they be likely to be below the arerage. The inmates are, for the most part, elected after great exertion, and the friends of a phthisical idiot would scarcely be likely to undertake the trouble for a manifestly short-lived child, even if the rules of the institution did not exclude it.

During the past eight years, from 1859 to 1866 inclusive, there have been 201 deaths. During this time there have been two epidemics of measles, one of scarlet fever, and two of whooping.cough, which have all added to the mortality. Moreover, a large proportion of the patients who succumbed to these epidemic diseases were those who would in all probability have eventually died of phthisis but for their interven. tion. Notwithstanding this circumstance there remains the fact, which my notes record, that, of the whole mortality, 39.8 is due to phthisis. To appreciate fully the meaning of these figures, it is necessary to consider the rate of mortality which rules amongst an idiot population. My notes show that, taking the last eight years, in some of which there were epidemics, while others were entirely free therefrom, the mortality presented an average of about 73.3 per 1000 ; whereas the mortality of the district in which the asylum is situated was about 18 per 1000 .

\begin{tabular}{|c|c|c|c|c|}
\hline Date. & $\begin{array}{c}\text { Average } \\
\text { popu- } \\
\text { lation. }\end{array}$ & $\begin{array}{c}\text { Gross } \\
\text { mortality. }\end{array}$ & $\begin{array}{l}\text { Deaths } \\
\text { from } \\
\text { phthisis. }\end{array}$ & $\longrightarrow$ \\
\hline 1859 & $285 \frac{3}{4}$ & 13 & 7 & \multirow{8}{*}{$\begin{array}{l}\text { Epidemic of typhoid. } \\
\text { Epidemic of measles. } \\
\text { Epidemic of measles and } \\
\text { scarlatina. }\end{array}$} \\
\hline 1860 & $308^{\frac{3}{3}}$ & 22 & 7 & \\
\hline 1861 & $318 \frac{1}{3}$ & 23 & 13 & \\
\hline 1862 & 322 & 33 & 8 & \\
\hline 1863 & $344 \frac{1}{2}$ & 47 & 15 & \\
\hline 1864 & $369 \frac{\pi}{6}$ & 19 & 10 & \\
\hline 1865 & $412 \frac{3}{4}$ & 13 & 9 & \\
\hline 1866 & $423 \frac{1}{2}$ & 31 & 11 & \\
\hline
\end{tabular}

The statistics of London show that the deaths from phthisis constitute 115 per 1000 of the general mortality. My notes of the causes of death at Earlswood indicate that phthisis was the actual cause of death in 398 per 1000 of the general mortality. The significance, however, of this, as before observed, can only be rightly estimated by recollecting that the general mortality is four times that of an ordinary community.

It will be obvious that, in consequence of the greater readiness with which idiots succumb to epidemic or other diseases, the proportional deaths from phthisis are thereby much decreased. This element may be fully brought out by dividing the eight years; bringing together the four epidemic years, and comparing them with the four non-epidemic years. It will then be seen that during the epidemic years 1860 , ' 62 , ' 63 , and ' 66 , the deaths from phthisis numbered 297 per 1000 of the general mortality, or considerably more than twice the ratio which rules in London; while in the non-epidemic years 1859 , ' 61 , ' 64 , and ' 65 , the deaths from phthisis reached the enormous proportion of 57058 per 1000 of the general mortality. I now propose to present a tabular view of the age and sex of those who died from phthisis.

\begin{tabular}{|c|c|c|c|c|c|}
\hline Age. & & Male. & & Female. & \\
\hline 7 & … & 1 & $\ldots \ldots$ & 0 & ....... \\
\hline 8 & $\ldots \ldots$ & 1 & $\ldots \ldots$ & 0 & ....... \\
\hline 9 & ....... & 1 & $\ldots \ldots$ & 2 & $\ldots \ldots$ \\
\hline 10 & $\ldots \ldots$ & 3 & $\ldots \ldots$ & 0 & $\ldots \ldots$ \\
\hline 11 & …... & 2 & $\ldots \ldots$ & 1 & $\ldots \ldots$ \\
\hline 12 & $\ldots \ldots$ & 3 & $\ldots \ldots$ & 1 & $\ldots \ldots$ \\
\hline 13 & ...... & 6 & $\ldots \ldots$ & 2 & $\ldots \ldots$ \\
\hline 14 & ....... & 5 & $\ldots \ldots$ & 2 & $\ldots \ldots$ \\
\hline 15 & $\ldots \ldots$ & 1 & $\ldots \ldots$ & 0 & $\ldots \ldots$ \\
\hline 16 & $\ldots \ldots$ & 4 & $\ldots \ldots$ & 1 & $\ldots \ldots$ \\
\hline 17 & $\ldots$ & 2 & $\ldots \ldots$ & 6 & $\ldots \ldots$ \\
\hline 18 & $\ldots \ldots$ & 4 & $\ldots \ldots$ & 3 & ....... \\
\hline 19 & $\ldots . .$. & 8 & $\ldots \ldots$ & 1 & $\ldots \ldots$ \\
\hline 20 & $\ldots \ldots$ & 7 & $\ldots \ldots$ & 1 & $\ldots \ldots$ \\
\hline 21 & $\cdots$ & 6 & $\ldots \ldots$ & 2 & ....... \\
\hline 23 & $\ldots$ & 2 & $\ldots \ldots$ & 0 & $\ldots \ldots$ \\
\hline 27 & $\ldots$ & 1 & $\cdots \cdots$ & 0 & $\ldots \ldots$ \\
\hline 29 & $\ldots \ldots$ & 1 & $\ldots \ldots$ & 0 & ........ \\
\hline & & 8 & & 22 & \\
\hline
\end{tabular}

Dividing the ages into quinquennial periods, it will be observed that the greatest mortality from phthisis was from fifteen to twenty years of age. 


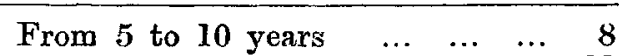

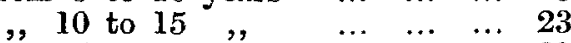

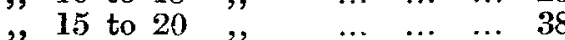

10

, 25 to 30

The above" details have "reference solely" to ante-mortem diagnosis, and have included only cases where the death was evidently caused by phthisis. I have, however, made an analysis of the last hundred of my post-mortem records, and I find that no fewer than 62 per cent. were subjects of tubercular deposit. There were 62 males, and tubercular deposit was found in 49 instances, or 79.03 per cent. There were 38 females, and of these, 13, or 34 per cent., were tubercular.

$$
\text { ( } T \text { o be coneluded.) }
$$

\section{IODINE INHALATION IN THE TREATMENT OF DIPHTHERIA.}

\section{BX J. WARING-CURRAN, L.K.Q.C.P.I.}

To those interested in the subject of Diphtheria, the experience of a recent epidemic with which we have been visited, and the result of the treatment adopted, may not prove uninteresting nor disadvantageous.

The disease broke out sporadically on the 2nd of January, by attacking the daughter of a Coast-guardsman residing at Pevensey station. The girl had been out of health for a couple of days before advice was sought. On being visited, I reremarker enlargement of the tonsils, with one of the usual membranous specks indicative of the disease developed on the left; the glands of the neck on the corresponding side were enlarged; there was no pain complained of on deglutition, but a good deal of fever. The tonsil I freely cauterised, prescribed a solution of chlorine gargle, and a dose of calomel. The following day there was an aggravation of all the symptoms, with an increase in extent of membranous deposition; the voice was husky, breath fetid, pain in deglutition, and a croupy congh. I applied a blister to the exterior of the throat, pre scribed powerful tonics, and ordered brandy, wine, and beeftea alternately, every hour. Towards evening the breathing became more complicated, blue blood began to circulate, and the girl died in a fit the ensuing morning.

On the 4th of January two additional cases occurred, one in the house adjoining the first, the other in a farmer's cottage wome quarter of a mile distant, where there was no communication with the Coast-guard buildings in which the disease began. Both cases I treated in a similar manner to the first, and both died, one in a characteristic convulsion, and on passed quietly away. After an interval of several days, six new cases commenced, just as the consternation was beginning to subside, and when we had hoped the disease had left us these I treated by local cauterisation, with nitrate of silver where it was practicable, and the inhalation of iodine in hot vinegar and sage, prescribing large quantities of wine and ammonia, strong beef-tea, and ice, and counter-irritants over the chest, as in the first three. Some of these were truly formidable cases, manifesting symptoms which, writers on the subject tell us, once evinced, are never recovered from; but all ultimately recovered, with ten others which subsequently occurred. The wives and children of the artillery-men stationed in the Martello towers in the neighbourhood in several instances became affected; some deaths happened, and the disease only yielded to treatment when the doctor in attendance, at my suggestion, altered his plan, and had recourse to the iodine inhalation, which eventually turned out as efficacious with him as with me. Of its value in this disease I speak fearlessly, and truthfully consider that many of the cases I had under my charge must assuredly have succumbed, had it not been for the service rendered by the iodine. To those to whose lot may unfortunately fall the treatment of diphtheria, I would earnestly recommend a fair and early trial of inhalation of iodine combined with sage and hot vinegar. The sage I look upon as a useful adjunct, not relying solely on the hexameter, "Cur moriatur homo, cui crescit salvia in horto?"

but believing it possesses many sedatire virtues when employed as an inhalation in throat affections.

The Admiralty, through their officer, gave every assistance, and afforded every facility in the attempts made to arrest the progress of what seemed an exceedingly virulent epidemic. The water-tanks connected with the buildings were opened and examined, and a thorough investigation made to account for the presence of the disease, but with little avail; doubtless, however, the development and diffusion of the disease depended on certain atmospheric and hygieric conditions communicable through the air or water, which, in the present instance, we were unable to determine or account for. Nevertheless, my experience in combating the epidemic has tanght me that the direct influence of iodine vapour upon the morbid product, or on the portions of respiratory apparatus still unaffected, is such as either to arrest the power of advancement in the false membrune by destroying its virus, or by producing a thickened, consequently less susceptible, condition of the mucous lining of the tract, whereby it bestows a power of resistance against the deposit and prevents a further spread of the materies morbi.

The frightful mortality which attends the treatment of diphtheria, and the horror in which its presence is held by the profession generally, actuate me in trespassing on your space to recommend a remedy which $I$ now believe, if properly and judicionsly employed, together with tonics and a stimulating regimen, to be the remedy for the disease, and the only method of scientifically coping with it.

Bexhill, St. Leonard's, August, 1867.

\section{ON}

\section{A CASE OF TUBERCULAR MENINGITIS.}

\section{BY H. KNOWLES, L.R.C.P. EDIN., \&c.}

ON the 29th of April, 1867, I was sent for to see Mr. R. $\mathrm{B}$-, aged twenty-seven. I found him lying on the bed in a semi-comatose state. I could with difficulty rouse him; and, after answering a question, he would relapse into his former condition. His tongue was dry and slightly furred; skin moist; pulse 110; bowels constipated; urine scantysp. gr. 1034; face pale; pupils much dilated, equal; no intolerance of light. I ordered him five grains of calomel, to be followed by a saline aperient draught. To have beef-tea and milk diet. I saw him again in the evening. His pulse was 100 ; bowels had acted well. He was more sensible, and had had three hours' sleep. To take bicarbonate of potash, fifteen grains; iodide of potash, eight grains; camphor mixture, one ounce : every three hours.

A pril 30th. - I found him worse. He cannot pass his urine; pulse 112 ; mouth nearly closed; lower jaw fixed; great difficulty in getting hirn to take nourishment. His face and con junctivæ much congested. I ordered his hair to be cut off, ice applied to the head, a large blister to the back of the neck, and eight leeches to the temples.

May lst. - He continues much about the same, but the bowels are constipated. To have a turpentine enema.

2nd.-Continues to get worse. He has clonic spasms.

From the 3rd to the 5th of May he gradually got worse. On passing the catheter on the latter day I found the bladder empty.

6th.-He has still suppression of urine, with stertorous breathing, and is gradually sinking.

7th. - The patient died to-day at eleven P.Mr.

On the 8th of May I made a post-mortem examination. On removing the calvaria, I found extravasation of blood on the dura mater, and effusion of serum beneath the arachnoid. There were a few miliary tubercles lying on the upper surface of the cerebrum, about an inch to the right of the superior longitudinal sinus. On opening the lateral ventricles $I$ observed masses of cheesy deposit adhering to both choroid plexuses, but much more connected with the left than the right. There was no deposit at the base of the brain, or in the fissure of Sylvius. The lungs were quite free from tubercular deposit. There was fatty degeneration of the heart, the walls of which were thin and llabby. The aorta and semilunar valves were healthy. On examining some of the cheesy deposit under the microscope, I found that it consisted of round and oval corpuscles, containing granules embedded in a stroma.

The somewhat remarkable features in the case were, the absence of vomiting, of irregularity or contraction of the pupils, or intolerance of light; no paralysis of the sphincter ani in the third stage; together with the absence of tubercular deposit in the lungs, and the exceptional situation of the deposit in the brain.

Barking-road, Canning-town, E., Sept. 1867. 